\title{
PEMBAHARUAN HUKUM WARIS ISLAM DI TURKI
}

\author{
Umar Faruq Thohir*
}

\begin{abstract}
Abstact
It is inevitable that a legal enactment, or reform of Islamic family law in various Muslim countries or countries with a majority Muslim population in the world. This is because the existing law (valid) is still not revealed or has been revealed but is considered not in accordance with the era anymore, due to the different "context" between the past and the present. As Anderson said, Islamic law in Islamic countries was not static at all.

The form of renewal that is carried out differs from country to country. First, there are some countries that carry out reforms in the form of laws. Second, there are some countries that carry out reforms based on the decree of the president or king. Third, there are some countries that carry out reforms in the form of judicial provisions.

The country of Turkey is the first country to carry out renewal in family law. Updates are carried out in the form of laws. For Turkish Muslims, Hanafi is a school that underlies the religious life formally until 1926, before the existence of legislation legislation that was eclectically codified. The Islamic Civil Law or what is called $\neg$ Majallat al-Ahkâm al-liAdliyah, which most of the material is based on Hanaf madî actually has been prepared in Turkey since 1876, although it is not comprehensive, because it does not include family law and inheritance law.
\end{abstract}

Keywords: reform of Islamic, Waris, and Turkish Muslims

* Dosen Institut Ilmu Keislaman Zainul Hasan Genggong Kraksaan 


\section{PENDAHULUAN}

Merupakan sebuah keniscayaan terjadinya sebuah pengundangan hukum, atau reformasi hukum keluarga Islam di berbagai Negara muslim atau Negara berpenduduk mayoritas muslim di dunia. Hal itu disebabkan karena hukum yang ada (berlaku) masih belum diqanûnkan atau sudah diqanûnkan namun dianggap tidak sesuai dengan zamannya lagi, akibat berbedanya "context" antara masa lalu dengan masa kini. Seperti kata Anderson, hukum Islam di negara-negara Islam ternyata tidak bersifat statik sama sekali. ${ }^{1}$

Bentuk pembaharuan yang dilakukan berbeda antara satu negara dengan negara yang lain. Pertama, ada beberapa Negara yang melakukan pembaharuan dalam bentuk undang-undang. Kedua, ada sebagian Negara yang melakukan pembaharuan dengan berdasarkan dekrit presiden atau raja. Ketiga, ada beberapa Negara yang melakukan pembaharuan dalam bentuk ketetapan-ketetapan hakim. ${ }^{2}$

Negara Turki merupakan Negara pertama yang melakukan pembaharuan dalam hukum keluarga. Pembaharuan dilakukan dalam bentuk undang-undang. Bagi muslim Turki, Hanafi adalah madzhab yang melatari kehidupan keberagamaan secara formal hingga tahun $1926,{ }^{3}$ sebelum ada kebijakan legislasi undang-undang yang dikodifikasi secara eklektikal. ${ }^{4}$ Undang-Undang Sipil Islam atau yang disebut Majallat al-Ahkâm al-Adliyah, yang sebagian besar materinya didasarkan pada madzhab Hanafî sebenarnya telah dipersiapkan di Turki sejak tahun 1876, sekalipun belum komprehensif, karena tidak memasukkan

1 J.N.D. Anderson, Hukum Islam di Dunia Modern, alih bahasa Machnun Husein (Surabaya: Amarpress, 1990), hlm. 89-90.

2 H. M. Atho' Muzdhar dan Khoiruddin Nasution (ed.), Hukum Keluarga di Dunia Islam Modern (Jakarta: Ciputat Press, 2003), hlm 1; juga dapat dilihat di Kiran Gupta, "Polygamy Law Reform in Modern Muslim States: A Study in Comparative Law," dalam Islamic and Comparative Law Review, vol. xii, no.2 (ttp.: Summer, 1992), hlm. 114-154, pada hlm. 127.

3 Di Turki, madzhab Hanafi adalah madzhab mayoritas. Hal itu juga berpengaruh pada pembentukan Turki yang rasional, sebagaimana karakteristik madzhab Hanafi. Lihat Seyyed Hossein Nasr, "Islam," dalam Arvind Sharma (ed.), Our Religious (New York: Harper Collins, 1993), hlm. 427-532, pada hlm. 466.

4 Tahir Mahmood, Personal Law in Islamic Countries; History, Text, Comparative Analysis (New Delhi: Academy of Law and Religion, 1987), hlm. 264. 
hukum keluarga dan hukum waris. ${ }^{5}$

Akhirnya pembaharuan pun dilakukan, sehingga tercipta UndangUndang The Turkish Civil Code. Materi pembaharuan dalam undangundang ini adalah seputar Hukum Perkawinan (pertunangan, umur pernikahan, mahrom, poligami, resepsi pernikahan, pembatalan pernikahan), Perceraian dan Pemisahan, Kompensasi, dan Hukum Waris. ${ }^{6}$

Secara singkat dan padat, kajian ini akan membahas tentang sejarah pembaharuan hukum keluarga Turki dan faktor-faktor yang mempengaruhinya sejak masa Utsmani sampai Turki terbentuk menjadi Republik, menjelaskan unsur-unsur pembaharuan hukum keluarga Turki, khususnya yang terkait dengan hukum waris.

\section{PEMBAHASAN}

\section{A. Sejarah Singkat Republik Turki}

Negara Turki merupakan negara yang berada di dua benua, yaitu benua Asia dan benua Eropa. Sekitar 95 persen dari wilayah seluas $780.576 \mathrm{~km}^{2}$ ini berada di benua Asia, selebihnya masuk ke kawasan Eropa. Ada yang menduga bangsa Hittiti yang menjadi penduduk pertama di kawasan ini, berasal dari Eropa, dugaan yang lebih populer memperkirakan orang Hittiti berasal dari Asia Tengah. Berdasarkan hasil sensus tahun 1992, jumlah penduduknya sekitar 58.436 .000 jiwa $^{7}$ dengan tingkat kepadatan penduduk 71.1 jiwa $/ \mathrm{km}^{2}$, dan prosentase tempat tinggal 53\% hidup di perkotaan serta $47 \%$ lainnya tinggal di pedesaan. ${ }^{8}$

Memasuki tahun pertama Masehi, wilayah Turki yang saat itu

5 Tahir Mahmood, Family Law Reform in The Muslim World (New Delhi: N.M. TRIPATHI PVT. LTD., 1972), hlm. 15; Isroqunnajah, "Hukum Keluarga Islam di Republik Turki,” dalam M. Atho’ Muzdhar dan Khoiruddin Nasution (ed.), Hukum Keluarga di Dunia Islam Modern (Jakarta: Ciputat Press, 2003), hlm. 36-52, pada hlm. 37.

6 Tahir Mahmood, Family Law Reform, hlm. 18-24.

7 The world book of Encyclopedia, Turki, Vol. 19 (USA: World book Inc., 1997), hlm. 413.

8 Isroqunnajah, Hukum Keluarga Islam, hlm. 36. 
bernama Kerajaan Bizantium memang dikuasai Romawi selama empat abad. ${ }^{9}$ Kekuasaan Romawi dijatuhkan kaum Barbar. Pada masa inilah ibukota kerajaan dipindahkan dari Roma ke Konstantinopel (sekarang Istambul). ${ }^{10}$ Pada abad ke-12 Bizantium jatuh ke dalam kekuasaan Kerajaan Ottoman yang dipimpin Raja Utsman I. Ini merupakan masa keemasan Turki Ottoman. ${ }^{11}$

Pada masa inilah pemerintahan Turki Ottoman memperoleh pengaruh Islam yang kuat. Bahkan sepeninggal Khulafâ' al-Râsyiddîn, Turki menganut sistem Khilâfah Islâmiyah di bawah dinasti Utsmaniyah. Wilayahnya meliputi jazirah Arab, Balkan, Hongaria hingga kawasan Afrika Utara. Namun kekhalifahan itu hancur karena konflik internal akibat perebutan kekuasaan yang melibatkan intervensi sejumlah negara asing. ${ }^{12}$

Bermula dari perlawanan terhadap campur tangan asing yang dipimpin Musthofa Kemal, aksi perjuangan berubah menjadi penentangan terhadap kekuasaan Khalîfah. Moment kehancuran Khilâfah Islâmiyah sendiri terjadi saat rakyat Turki melalui wakil-wakilnya mengeluarkan Piagam Nasional (al-Mitsâq al-Wathonî). Sejak itu, Turki menjadi sebuah negara tersendiri, terpisah dari wilayah-wilayah yang dulu merupakan kesatuan Khilafah Islamiyah. Khalifah Abdul Majid yang terakhir berkuasa, terusir ke luar Turki. Tetapi mereka dapat

9 Sami bin Abdullah al-Maghlûts, Atlas Perang Salib: Mengungkap Peristiwa Berdarah Abad Pertengahan, alih bahasa Fuad Syaifuddin Nur (Jakarta Timur: Almahira, 2009), hlm. 13.

${ }^{10}$ Bernad Lewis, The Middle East: A Brief History of The Last 2000 Years (New York: Scribner, 1996), hlm. 33-38.

${ }^{11}$ Kata Ottoman berasal dari nama nenek moyang mereka, yakni Utsman (nama khalifah ideal) yang kemudian menjadi Utsmani dan akhirnya disebut Ottoman. Ottoman adalah salah satu dinasti besar dan lama di dunia. Sejak abad 13 hingga abad 19 (tepatnya 1922) kerajaan ini telah diperintah oleh 36 sultan. Utsman adalah sultan pertama, kemudian diikuti sultan lainnya dengan berdasarkan pada hubungan darah dan garis keturunan bapak. Ottoman mencapai puncak kejayaannya pada masa pemerintahab Sulaiman pada abad ke 16. wilayah kekuasaan kerajaan melebar dari Budapes ke Yaman, mulai dari Baghdad sampai ke Aljazair, bahkan pada tahun 1529 pasukan Sulaiman sudah hampir menguasasi Wina. Lihat Akbar S. Ahmed, Citra Muslim: Tinjauan sejarah dan Sosiologi, alih bahasa Nunding Ram dan H. Ramli Yakub (Jakarta: Erlangga, 1992), hlm. 71.

${ }^{12}$ Ira M. Lapidus, Sejarah Sosial Ummat Islam; Bagian Ketiga, alih bahasa Ghufron A. Mas'adi (Jakarta: PT. Raja Grafindo Persada, 1999), hlm.80-84. 
bertahan di Istanbul dan daerah pedalamannya. ${ }^{13}$

Mustafa Kemal menjelaskan pada anggota Majelis Nasional Agung, bahwa pemerintah nasional didasarkan pada prinsip pokok populisme (kerakyatan), yang berarti bahwa kedaulatan dan semua kekuatan administrasi harus langsung diberikan kepada rakyat. Konsekuensi logis dari prinsip ini adalah terhapusnya kesultanan dan kekhalifahan.

Kesultanan dihapuskan pada tanggal 1 Nopember 1922, dengan undang-undang yang disahkan oleh Majelis Nasional Agung setelah melalui debat yang panjang. Penghapusan jabatan sultan berarti menghilangkan dualisme dalam pemegang jabatan duniawi, yaitu raja Turki di satu pihak dan Majelis Negara di pihak lain. Semenjak penghapusan jabatan itu, kedaulatan berada di tangan Majelis Nasional Agung, dan kekuasan eksekutif berada di tangan majlis Negara. Maka terpisahlah dengan jelas kekuasaan eksekutif dari kekuasaan legislatif. Semenjak itu, Khlaifah Abdul Majid hanya merupakan lembaga keislaman Turki.

Pada 1923, disepakatilah berdirinya negara Turki dengan batasbatas wilayah seperti saat ini. Laut Hitam di utara; Irak, Suriah dan Laut Tengah di selatan; Laut Aegea di barat dan Iran serta Rusia di timur. Negara republik dengan ibukota Ankara itu, pertama kali dipimpin oleh Musthofa Kemal. Ia melakukan modernisasi besar-besaran dengan berkiblat ke Barat. Ia mengganti penggunaan huruf Arab dengan Latin, poligami dilarang dan wanita diberi kebebasan yang sama dengan pria. Kemal pun memperoleh gelar Bapak Bangsa Turki (Attaturk) sehingga dikenal sebagai Kemal Attaturk. ${ }^{14}$

Kebijakan-kebijakan Kemal banyak dilatari oleh pemikiran barat. Tujuan utama Turki Kemalis adalah pembangunan ekonomi dan modernisasi kultural. Untuk mewujudkan pembangunan ekonomi, Kemal meningkatkan produksi pertanian dengan mereduksi pajak dan berinvestasi dalam proyek jalan dan lintasan kereta api, memprakarsai pembangunan industri, menasionalisasikan pembangunan jalan,

${ }^{13}$ Bernad Lewis, The Middle East, hlm. 157; juga dapat dilihat di Akbar S. Ahmed, Citra Muslim, hlm. 75.

${ }^{14}$ Mustafa Kemal Attaturk ditetapkan sebagai Presiden Republik Turki sepanjang hidup. Selain berperan sebagai kepala pemerintahan, Kemal juga mengetuai Partai Republik yang telah mengantarkannya menjadi Presiden pada tahun 1923. lihat Ira M. Lapidus, Sejarah Sosial Ummat Islam, hlm. 88. 
pelabuhan dan pertambangan, mengembangkan industri pengolahan bahan pokok, mendirikan Bank Sumer untuk mendanai perusahaan kecil tekstil, kertas, kaca, dan gula, hingga akhirnya pada dekade 1920. an dan 1930-an disiapkanlah dasar-dasar bagi kelahiran sebuah ekonomi industri modern.

Sedangkan untuk mewujudkan modernisasi kulturalnya, Kemal berusaha merenggangkan keterikatan masyarakat umum terhadap Islam (klasik), dan mengarahkan mereka kepada pola kehidupan barat yang sekuler. Kemal menghapuskan sejumlah lembaga organisasi Islam (eksklusif-tradisionalis). Bahkan pada tahun 1925 beberapa tharîqah sufi dinyatakan sebagai organisasi terlarang (ilegal) dan dihancurkan. Pada tahun 1928 diberlakukan tulisan latin menggantikan tulisan Arab, dan mulai dilancarkan upaya memurnikan bahasa Turki dari muatan bahasa Arab dan Persi. Pada tahun 1935, seluruh warga Turki diharuskan menggunakan nama kecil sebagaimana yang berlaku dalam penggunaan pola nama Barat. ${ }^{15}$

Reformasi dekade 1920-an dan 1930-an membawakan perubahan yang lebih radikal. Undang-undang keluarga 1924 mengharamkan

${ }^{15}$ Ibid., hlm. 91; Akbar S. Ahmed menambahkan, kebijakan-kebijakan eropanisasi yang dikeluarkan Mustafa Kemal disamping karena gesekan dengan peradaban Eropa, sebenarnya juga tidak lepas dari latar belakang bangsa Turki yang sudah bosan dengan gaya hidup hedonis para Raja Turki Utsmani yang tidak mencerminkan keadilan bagi orang-orang kecil dan mendiskriminasikan wanita. Istana Topkali (nama istana kerajaan Ottoman) terletak di atas tanah seluas 14 hektar dan menghadap ke tiga lautan. Di tengah istana itu terletak sebuah Harem (ruangan khusus) yang dirancang dengan istimewa untuk ditinggali sultan. Ia hidup, bermain, dan meninggal dunia di Harem itu. Dari Harem itu pula, sultan menjalankan roda pemerintahan. Gaun sutra hanya dipakai sekali, setelah itu dibuang. Di Harem itu tinggal pula para gundik tawanan dan pesuruh Harem dalam 350 kamar. Berbagai ragam wanita dengan kulit dan kasta yang berbeda dibawa, dibeli, atau diculik ke dalam Harem. Para anak kesayangan segera ditunjuk untuk memerintah di wilayah yang amat luas, sedangkan anak yang dibenci dikungkung di dalam Harem kamar yang mirip kandang agar mereka lambat laun menjadi gila dalam kesendirian mereka. Pada abad ke-17, Sultan Ibrahim yang karena kecanduan obat bius memerintahkan untuk menenggelamkan 280 gundiknya di selat Bosphorus. Karena gaya hidup hedonis para Raja yang muslim inilah, penduduk Turki akhirnya enggan untuk menggunakan simbol-simbol keislaman. Namun nilai-nilai keislaman tetap diaplikasikan dalam keseharian, pemerintahan, politik, dan pergaulan. lihat Akbar S. Ahmed, Discovering Islam, Making Sense of Muslim History and Society (London\&New York: Routledge\&Kegan Paul, 1988), hlm. 66-67; idem, Living Islam: from Samarkand to Stornoway (New York: Facts on File, 1994), hlm. 100-104.; J.N.D. Anderson, Hukum Islam, hlm. 21-27. 
poligami, menjadikan suami dan isteri berkedudukan sama dalam perceraian, ${ }^{16}$ dan sejak saat itu perceraian harus dijatuhkan di pengadilan dengan syarat-syarat tertentu, tidak semata-mata hak prerogatif suami. ${ }^{17}$

Konstitusi menegakkan hak persamaan wanita dalam pendidikan dan dalam pekerjaan, dan pada tahun 1934 kaum wanita diberi hak untuk dicalonkan dalam pemilihan nasional. Pada tahun 1935, beberapa perwakilan wanita terpilih dalam parlemen Turki. Perubahan dalam hal sikap dan prinsip hukum menjadi basis utama bagi pengembangan partisipasi wanita di dalam kehidupan publik bangsa Turki. ${ }^{18}$

\section{B. Sejarah Reformasi Hukum Keluarga Di Turki}

Penerapan hukum Islam dalam terma kenegaraan secara serius dan sistematis dimulai pada masa Umar bin Abdul Aziz. Negara pada saat itu merupakan lembaga eksekutif yang menerapkan hukum Islam sebagaimana dirumuskan oleh otorita hukum setempat di masingmasing daerah. Kumpulan hukum (figh) yang mengatur hal-hal pokok dilaksanakan secara seragam. Namun berkaitan dengan hal-hal yang detail banyak terjadi perbedaan karena praktek-praktek setempat dan variasi-variasi yang berbeda sebagai hasil ijtihad para ulama. ${ }^{19}$

Legislasi hukum-hukum baru untuk melengkapi hukum Islam dalam skala besar telah dilakukan oleh penguasa-penguasa Turki Usmani pada abad ke-10 H/16 M yang menghasilkan qanun (canon). Qanun adalah produk kesultanan, dan bukan produk kekhalifahan. ${ }^{20}$

Pembaruan hukum Islam dalam format perundang-undangan hukum keluarga dimulai pada tahun 1917 dengan disahkannya The Ottoman Law of Family Rights (Undang-undang tentang hak-hak

${ }^{16}$ Muhammad Muslehuddin, "Islamic Social System," dalam Studies in Islamic Law, Religion and Sosiety (New Delhi: H.S. Bathia, 1989), hlm. 334-347, pada hlm. 344.

${ }^{17}$ Akh. Minhaji, Islamic Law and Local Tradition: A Socio-Historical Approach (Yogyakarta: Kurnia Kalam Semesta, 2008), hlm. 155.

${ }^{18}$ Kedudukan kaum wanita dalam masyarakat Islam merupakan cermin keberadaan Islam. Bilamana masyarakat Islam Berjaya, maka kedudukan kaum wanitanya pun akan demikian pula. Lihat Akbar S. Ahmed, Citra Islam, hlm. 205.

${ }^{19}$ Fazlur Rahman, Islam, alih bahasa Ahsin Mohammad, cet. Ke-IV (Bandung: Pustaka, 2000), hlm. 108.

${ }^{20}$ Ibid., 109. 
keluarga) oleh Pemerintah Turki. ${ }^{21}$ Pembaruan hukum keluarga di Turki merupakan tonggak sejarah pembaruan hukum keluarga di dunia Islam dan mempunyai pengaruh yang besar terhadap perkembangan hukum keluarga di negara-negara lain. ${ }^{22}$

Eksistensi hukum keluarga di dunia sebagai hukum positif mempunyai bentuk yang berbeda-beda. Tahir Mahmood membagi tiga kategori negara berdasarkan hukum keluarga yang dianut, yaitu (1). Negara yang menerapkan hukum keluarga tradisional, (2). Negara yang menerapkan hukum keluarga sekuler, (3). Negara yang menerapkan hukum keluarga yang telah diperbaharui melalui proses legislasi modern. ${ }^{23}$

Turki, jika dilihat dari sejarah berdirinya, sebenarnya masuk ke tiga kategori tersebut. Pada saat pemerintahan Utsmani berkuasa, hukum keluarga pada saat ini masih bersifat sangat tradisional, karena hanya berkiblat pada madzhab Hanafi saja. ${ }^{24}$ Pada masa Mustafa Kemal, sekularisasi hukum keluarga nampak ketika Turki mengadopsi The Swiss Civil Code tahun 1912. Ketika Turki menjadi Republik, maka hukum keluarga diciptakan melalui legislatif, layaknya Negara Republik lainnya, hal itu terwujud dalam proses amandemen terhadap The Turkish Civil Code of 1926. Namun, jika kategorisasi Tahir Mahmood tersebut dikaitkan dengan hukum keluarga Turki yang berlaku saat ini, maka Turki termasuk pada kelompok ketiga, dimana hukum keluarga Turki diperbaharui melalui proses legislasi modern. ${ }^{25}$

Reformasi hukum keluarga Turki dalam bentuk undang-undang dimulai sejak tahun 1917 dengan lahirnya Qanun-i Qarar Huquq alIllah al-Utsmaniah (hukum Utsmani yang mengatur hak-hak keluarga)

${ }^{21}$ J.N.D. Anderson, Hukum Islam, hlm. 27; juga dapat dilihat di idem, Law Reform in the Muslim World (London: The Athlone Press, 1976), hlm.43; juga dapat dilihat di Tahir Mahmood, Family Law Reform, hlm. 17; juga dapat dilihat di Akh. Minhaji, Islamic Law, hlm. 155.

${ }^{22}$ Khoiruddin Nasution, Status Wanita, hlm. 93.

${ }^{23}$ Tahir Mahmood, Family Law Reform, hlm. 3-8.

24 J.N.D. Anderson, Hukum Islam, hlm. 57-58.

25 Tahir Mahmood, Family Law Reform, hlm. 7; bandingkan dengan Udjang Tholib, "The Relation Between the Kanûn and the Sharîa in the Ottoman Empire $\left(15^{\text {th }}-17^{\text {th }}\right.$ Centuries)," dalam Islam 8 Development: A Politico Religious Response (Jakarta: Titian Ilahi Press, 1997), hlm. 45-61, pada hlm. 45-48; Sherman A. Jackson, Islamic Law and The State: The Continental Jurisprudence of Shihâb al-Dîn al-Qarâfî (Netherland: E.J. Brill, 1996), hlm. xviii. 
yang akhirnya menjadi inspirasi bagi berbagai Negara muslim lain untuk mengundangkan hukum keluarga. Namun munculnya undang-undang perkawinan 1917 itu tentunya tidak terlepas dari proses panjang pengundangan yang telah dilalui. Disinilah letak signifikansi memahami sejarah reformasi dan kodifikasi hukum keluarga Turki. Kenapa muncul ide untuk mengeluarkan undang-undang, padahal sejak 1300-1922 Turki menganut sistem kerajaan, dimana peraturan dan kebijakan Negara ditentukan oleh titah sang Raja?

Ketika Kerajaan Utsmani masih berkuasa, Kerajaan memberlakukan sistem yudisial dan legal yang digabungkan dengan syari'ah (khususnya yurisprudensi madzhab Hanafi) dimana pengadilan diarahkan untuk menetapkan keputusan dalam berbagai kasus. Sistem ini ditopang oleh lembaga keagamaan (religious institution) yang nyaris independen dari kekuasaan Sultan (kepala pemerintahan). Lembaga keagamaan kerap kali diidentikkan dengan lembaga pemerintah itu sendiri.

Pada pucuk birokrasinya, lembaga ini dipimpin oleh seorang mufti (syaikh al-Islam). Meskipun lembaga mufti dipilih dan sewaktu-waktu dapat diberhentikan oleh seorang Sultan, namun secara norma sosial, kedudukan mufti relatif lebih tinggi dan disegani dibandingkan Sultan. Hal itu dikarenakan sikap religius mufti yang berbeda dengan sikap hedonis yang dimiliki Sultan. ${ }^{26}$

Sultan tidak boleh sewenang-wenang memberlakukan hukum syari'ah tanpa legitimasi berupa fatwa dari lembaga mufti. Dipihak lain, mufti memiliki kewenangan untuk memilih para hakim (Qâdli) yang mengatur pemberlakuan syari'ah di seluruh wilayah kerajaan. Namun pada masa awal abad 19, bersamaan dengan lengsernya kekuasaan Utsmani, semua lembaga-lembaga keagamaan ini tidak lagi diberlakukan, untuk sistematisasi serta kodifikasi sistem hukum, dimana sebelumnya pada tahun 1839 dikeluarkan Dekrit Imperium Hatt-i Syarif sebagai pondasi bagi rezim legislatif modern. ${ }^{27}$

Selanjutnya, untuk mengantisipasi maraknya perdagangan, pada tahun 1850-1858 dikeluarkanlah undang-undang perdagangan dan

${ }^{26}$ Akbar S. Ahmed, Discovering Islam, hlm. 66-67; idem, Living Islam, hlm. 100104; J.N.D. Anderson, Hukum Islam, hlm. 21-27.

${ }^{27}$ Tahir Mahmood, Personal Law, hlm. 263; Isroqunnajah, Hukum Keluarga Islam, hlm. 38; bandingkan dengan Akh. Minhaji, Islamic Law, hlm. 153. 
pidana yang sebagian rumusannya diambil dari hukum madzhab Hanafi dan sebagain yang lain dari hukum Perancis. Ide awal pembentukan undang-undang ini sebenarnya telah diperkenalkan sejak tahun 1840, dan pada tahun 1858 lahir undang-undang yang menguatkan pemilikan perorangan atas tanah. ${ }^{28}$

Nuansa sekularisasi hukum Islam di Turki sudah mulai Nampak. kodifikasi hukum dilakukan bersamaan dengan gelombang modernisasi hukum dan westernisasi yang sedang mengebu-gebu, seperti penetapan Majallat al-Ahkâm al-'Adliyah. Majallat al-Ahkâm al-'Adliyah adalah undang-undang sipil pertama yang ditetapkan di Turki, bahkan di dunia Islam, dimana rumusan materi Majallat al-Ahkâm al-'Adliyah sebagian didasarkan pada madzhab syari'ah dan sebagaian yang lain pada materi hukum Barat. ${ }^{29}$

Revolusi politik yang telah memporak-porandakan wilayah Imperium Utsmani dan melengserkan jabatan khalifah ikut memberi dampak terhadap penggantian undang-undang sipil tahun 1876, hukum keluarga (yang baru ditetapkan pada tahun 1915 dan 1917) dan hukum waris (dalam madzhab Hanafi) dengan undang-undang sipil baru yang diperbaharui pada tahun 1926, yang kemudian melahirkan The Turkish Civil Code (Undang-undang Sipil Turki).

Sebelumnya, untuk kasus-kasus yang berkaitan dengan status perseorangan, hubungan keluarga dan waris, telah diatur oleh pemerintah Utsmani secara formal dengan mengadopsi hukum dari madzhab Hanafi, tetapi hanya berlangsung sampai tahun 1915. Perubahan terjadi karena tuntutan perubahan kondisi sosial yang terjadi, sekalipun upaya perealisasiannya dilakukan secara bertahap.

Pada tahun 1915, Kerajaan mengeluarkan dua dekrit yang mereformasi hukum matrimonial (yang berhubungan dengan perkawinan) yang secara lokal terkait dengan hak-hak perempuan terhadap perceraian. Dalam dekrit tersebut digunakan prinsip takhayyûr (eklektik) dengan mengambil sumber dari madzhab Hanafi dan Hanbali. Di dalam dua dekrit tahun 1915 tersebut, dinyatakan bahwa perempuan

${ }^{28}$ Ira M. Lapidus, Sejarah Sosial Ummat Islam, hlm. 74.

29 Tahir Mahmood, Personal Law, hlm. 264; J.N.D. Anderson, Law Reform, hlm. 47-48; menurut Liebesny, Majallat al-Ahkâm al-Adliyah merupakan langkah awal kodifikasi hukum Islam yang berkiblat ke peradaban Barat. Lihat Akh. Minhaji, Islamic Law, hlm. 157. 
diperbolehkan mengupayakan perceraian atas dasar ditinggalkan suami atau karena penyakit yang dideritanya (suami). ${ }^{30}$

Pada tahun 1917, Kerajaan Utsmani mengeluarkan undang-undang tentang hukum matrimonial yang berjudul Qanun-i Qarar Huquq alIllah al-Utsmaniah yang berisi 156 pasal. Penetapannyapun didorong semangat takhayyûr, sebuah proses legislasi yang mulai menjadi trend pada era itu dan kemudian diperkenalkan ke seluruh dunia muslim sebagai cita-cita umum kodifikasi dan reformasi hukum keluarga. ${ }^{31} \mathrm{Di}$ turki sendiri hukum ini hanya bertahan kurang lebih dua tahun dan secara resmi dirubah pada tahun 1919.32

Pada tahun 1923, setelah konferensi perdamaian Lausanne, sebuah komite reformasi hukum dibentuk untuk merancang draft hukum sipil secara komprehensif dan status personal yang mendasarkan pada sumbersumber Islam. Tetapi komite tersebut gagal memenuhi harapan karena perbedaan pendapat yang dilatari oleh perbedaan visi dan misi antara sesama anggota komisi yang modernis, tradisionalis, dan nasionalis. Alasan lain adalah karena waktunya bersamaan dengan kehancuran khalifah Islam dan adanya deklarasi Turki sebagai Republik. Dibawah pemerintahan Mustafa Kemal Pasha, usaha kodifikasi hukum kembali dilakukan. Hasilnya, pada tahun 1924 konstitusi nasional baru ditetapkan dengan mengadopsi sitem hukum sipil yang mengharamkan poligami, menjadikan suami dan isteri berkedudukan sama dalam perceraian, dimana perceraian hanya diakui bila dilakukan di depan pengadilan. ${ }^{33}$

Pada tahun 1926, terciptalah undang-undang Sipil Turki (The Turkish Civil Code) yang berisi tentang Perkawinan (pertunangan, umur pernikahan, mahrom, poligami, resepsi pernikahan, pembatalan pernikahan), Perceraian dan Pemisahan, Kompensasi, dan Hukum Waris. Undang-undang 1926 ini lahir dengan mengadopsi The Swiss

30 Anderson menyebut tahun 1915 ini sebagai tahun reformasi hukum keluarga kedua. Lihat J.N.D. Anderson, Islamic Law in the Modern World (New York: New York University, 1959), hlm. 25.

${ }^{31}$ Ibid.

32 The Ottoman law of Family Rights 1917 ini merupakan bentuk reformasi hukum keluarga Turki yang lebih komprehensif. Lihat Akh. Minhaji, Islamic Law, hlm. 155; Tahir Mahmood, Family Law Reform, hlm. 16.

${ }^{33}$ Muhammad Muslehuddin, Islamic Social System, hlm. 344; bandingkan dengan Tahir Mahmood, Personal Law, hlm. 265. 
Civil Code tahun 1912 dengan sedikit perubahan sesuai dengan tuntutan kondisi Turki, karena para ahli hukum (komite) yang diserahi tugas memperbaharui undang-undang 1919 tersebut selama lima tahun tidak berhasil membuat draft undang-undang dimaksud. ${ }^{34}$

Sebagai Negara yang telah mengadopsi proses legislatif modern, maka amandemen terhadap undang-undang selalu dilakukan untuk kontekstualisasi hukum agar selalu sesuai dengan tuntutan zaman, demikian juga undang-undang 1926 tersebut, sejak tahun 1933 sampai 1965 tercatat telah dilakukan enam kali proses amandemen. ${ }^{35}$

Hasil amandemen ini antara lain berkaitan dengan ganti kerugian, dispensasi kawin, pasangan suami isteri diberi kesempatan untuk memperbaiki hubungan ketika pisah ranjang, juga penghapusan segala bentuk perceraian di luar pengadilan, serta tersedianya perceraian di pengadilan yang didasarkan pada kehendak masing-masing pihak (Pasal 125-132). Di samping itu pembayaran ganti kerugian terhadap pihak yang dirugikan akibat perceraian dapat dilaksanakan jika didukung dengan fakta yang kuat.

Proses amandemen terhadap Hukum Perdata Turki tahun 1926 selanjutnya berlangsung pada tahun 1988-1992. Amandemen tahun 1988 memberlakukan perceraian atas kesepakatan bersama (divorce by mutual consents), nafkah isteri dan penetapan sementara selama proses perceraian berlangsung. Amandemen tahun 1990 berkaitan dengan pertunangan, pasca perceraian dan adopsi. Proses amandemen yang dilakukan oleh legislative tersebut berakhir tahun $1992 .{ }^{36}$

\section{Unsur-Unsur Pembaharuan Dalam Hukum Waris Turki}

Pembaruan hukum keluarga di negara-negara Islam selalu melahirkan perdebatan di kalangan modernis-progresif dan tradisionaliskonservatif. Pembaruan hukum keluarga setidak-tidaknya berkaitan

34 Tahir Mahmood, Family Law Reform, hlm. 17; bandingkan dengan Kiran Gupta, Polygamy Law Reform, hlm. 115-116; Isroqunnajah, Hukum Keluarga Islam, hlm. 40. 41; Khoiruddin Nasution, Status Wanita, hlm. 93.

35 Tahir Mahmood, Personal Law, hlm. 265; Isroqunnajah, Hukum Keluarga Islam, hlm. 41.

${ }^{36}$ David Pearl and Werner Menski, Muslim Family Law, third edition, (London: Sweet and Maxwell, 1998), hlm. 21. 
dengan materi hukum yang dianggap out of date yang dilakukan dengan metode-metode tertentu. Pembaruan hukum keluarga di Turki menarik untuk disingkap lebih lanjut, khususnya yang berkaitan dengan hukum waris.

Salah satu prinsip Undang-undang Sipil Turki adalah kesetaraan antara laki-laki dan perempuan, demikian juga dalam kewarisan. Karena prinsip inilah, maka undang-undang Sipil Turki dalam ketentuan warisnya menetapkan pembagian yang sama, dalam artian perempuan dan laki-laki mendapatkan bagian yang sama dalam hal pembagian warisan, bukan lagi dua banding satu, melainkan satu banding satu.

Dalam fiqh klasik, baik madzhab Hanafi, Maliki, Syafi'i, atau Hanbali, sepakat bahwa pembagian waris antara perempuan dan lakilaki adalah satu banding dua berdasarkan firman Allah :

$$
\text { نيثيثنال ظح لثم ركذل مكدالوا يف هل ملا مكيصوي }
$$

Artinya : Allah mensyariatkan bagimu tentang( pembagian pusaka untuk) anak-anakmu yaitu bagian seorang anak lelaki sama dengan bagian dua orang anak perempuan. ${ }^{37}$

Berdasarkan sistem kewarisan satu banding satu ini, nampak jelas bahwa Republik Turki ingin mengangkat derajat wanita yang sebelumnya sangat didiskreditkan, khususnya pada masa pemerintahan Kerajaan Utsmani. ${ }^{38}$

Setelah berubah menjadi negara sekular, Turki mengambil hukum Swis tahun 1912 sebagai Undang-undang. ${ }^{39}$ Undang-Undang Sipil yang mulai diberlakukan pada tanggal 4 Oktober 1926 ini antara lain tentang: menerapkan monogami; melarang poligami dan memberikan persamaan hak antara pria dan wanita dalam memutuskan perkawinan dan perceraian. Sebagai konsekuensi dari persaman hak dan kewajiban ini hukum waris "berdasarkan Islam" dihapuskan. Selain itu undangundang sipil juga memberi kebebasan bagi perkawinan antar agama. Jadi dalam hal waris, Turki tidak menggunakan hukum Islam sama sekali, akan tetapi menggunakan undang-undang Swis yang memberikan hak yang sama antara laki-laki dan perempuan.

${ }^{37}$ An-Nisâ' (4): 11

${ }^{38}$ Akbar S. Ahmed, Discovering Islam, hlm. 66-67; idem, Living Islam, hlm. 100104.; J.N.D. Anderson, Hukum Islam, hlm. 21-27.

${ }^{39} \mathrm{Ibid}$. 
Mengenai waris ini dimuat dalam buku III Undang-undang Hukum Perdata Turki (Turkish Civil Code). Buku ini sama sekali tidak menyebutkan masalah wasiat, karena sebagaimana telah disebutkan di atas, bahwa undang-undang ini diadopsi dari Swiss Civil Code (nonislam) yang notabene tidak mengenal istilah wasiat.

Sebelum menggunakan Undang-Undang Hukum Perdata Swiss ini, Turki menggunakan hukum waris Islam berdasarkan mazhab Hanafi, karena mayoritas masyarakat Turki memang menganut mazhab Hanafi. ${ }^{40}$ Namun, sejak berubah menjadi negara sekular, Turki sedikit pun tidak lagi menggunakan sistem waris Islam, dan menggunakan sistem waris Hukum Perdata Swiss 1912 tersebut.

Ketentuan yang paling mencolok dalam sistem hukum waris Turki yang baru ini adalah adanya kedudukan yang sama antara laki-laki dan perempuan dalam perolehan bagian harta waris. Hal ini sebagai konsekuensi logis adanya kesamaan kedudukan mereka dalam hukum keluarga secara umum. ${ }^{41}$ Ini dapat dipahami, karena Swis memang menyetarakan hak antara laki-laki dan perempuan di dalam UndangUndang. Sistem seperti ini berbeda sama sekali dengan sistem hukum waris Islam yang diambil dari al-Quran, yang menyatakan bahwa bagian laki-laki dua kali lipat dari bagian perempuan. ${ }^{42}$

Ketetapan ini sudah menjadi ijma' kalangan ulama mazhab, karena pada umumnya mereka menganggap bahwa ayat terkait dengan waris merupakan ayat qath'i al-dilâlah yang sudah diatur secara rinci di dalam Al-Quran.

Buku III Turkish Civil Code juga menyebutkan bahwa anak-anak yang ditinggalkan oleh pewaris, mendapatkan bagian yang sama antara yang satu dengan yang lain, tidak ada pembedaan bagian berdasarkan gender atau kedudukan anak. Namun, di dalam undang-undang ini tidak menjelaskan status anak angkat. ${ }^{43}$

Undang-undang hukum waris dalam Turkish Civil Code ini terus digunakan sampai akhirnya Turki melakukan amandemen yang disetujui

\footnotetext{
40 Tahir Mahmood, Family Law, hlm. 24.

${ }^{41}$ Tahir Mahmood, Family Law, hlm. 4.

${ }^{42}$ An-Nisâ' (4): 11

${ }^{43}$ Pasal 439 The Turkish Civil Code, sebagaimana dikutip oleh Tahir Mahmood,
} Family Law, hlm. 5-6. 
oleh Majelis Nasional Turki pada 27 November 2001 dan disosialisasikan melalui Surat Kabar Harian Turki pada 8 Desember 2001. Amandemen ini memuat 1030 pasal. Isi amandemen ini yang terkait dengan hukum waris di Turki antara lain ${ }^{44}$ :

1. Suami dan Istri mempunyai kedudukan yang sama dalam keluarga, dan salah satu dari mereka bisa merepresentasikan keluarga di hadapan hukum atau pengadilan. ${ }^{45}$

2. Bagi anggota yang mempunyai gangguan mental, pemabuk, atau kelainan mental lainnya yang mengancam keluarga, atau orangorang sekitarnya, maka dengan ketetapan Pengadilan ia dapat di tempatkan di pusat pemulihan (rehabilitasi) untuk mendapatkan pengobatan dan perlindungan; dan dia juga berhak mendapatkan bagian waris sebagaimana ahli waris sehat. ${ }^{46}$

3. Apabila ada bagian yang sudah ditentukan, ketentuan tersebut dapat dibatalkan agar memperluas hak ahli waris yang lain. ${ }^{47}$

4. Dengan mengambil pertimbangan tradisi struktut keluarga di Turki, dalam keadaan apa pun, bibi atau paman yang mengurusi anak pewaris maka dapat mengambil sebagian tanah peninggalannya. ${ }^{48}$

5. Apabila Istri atau suami meninggal, untuk menjaga kelangsungan hidup ahli waris yang ditingglakan, maka suami atau istri yang masih hidup dapat mengklaim warisan yang ditinggalkan. Apabila alasannya hanya untuk menjaga kelangsungan dan kesejahteraan pihak pasangan yang ditinggalkan atau ahli waris lain yang sah untuk dapat memiliki tempat tinggal, maka hal itu dapat dipenuhi sebagai kepemilikan. ${ }^{49}$

6. Apabila harta waris berupa pertanian maka diserahkan kepada ahli waris yang berkompeten agar dapat menghasilkan profit, berdasarkan permintaan pihak yang hendak mengelola; dan apabila memungkin untuk dibagi, maka dibagi kepada yang mampu mengurusinya agar dapat menghasilkan profit. $^{50}$

\footnotetext{
${ }^{44} \mathrm{http}$.//www.sriwahyuni-suka.blogspot.com/pembaharuan hukum waris turki

${ }^{45}$ Pasal 188 The Turkish Civil Code

${ }^{46}$ Pasal 432 dan 437 The Turkish Civil Code

${ }^{47}$ Pasal 506 The Turkish Civil Code

${ }^{48}$ pasal 497 The Turkish Civil Code

${ }^{49}$ pasal 625 The Turkish Civil Code

${ }^{50}$ Pasal 659, 667 dan 668 The Turkish Civil Code
} 
7. Mengenai kepemilikan bersama antar ahli waris hendaknya mereka membuat sebuah ketentuan yang disepakati bersama untuk menghindari ketidakpuasan salah satu pihak dan meminta pembagian harta. ${ }^{51}$

Apabila kita cermati hasil amandemen di atas, bisa diambil kesimpulan: Pertama, dalam hal ahli waris, yang menjadi ahli waris adalah keluarga inti, yaitu suami atau istri yang ditinggalkan dan anak (nuclear family) sedangkan kerabat di luar keluarga inti dapat menjadi ahli waris apabila berjasa ikut memelihara ahli waris atau harta warisan. Kedua, mengenai status laki-laki dan perempuan, masih ditetapkan bahwa status laki-laki dan perempuan dalam keluarga sama, sehingga tidak membedakan mereka dalam perolehan harta peninggalan. Ketiga, Undang-undang di atas sudah membuat ketentuan tentang harta warisan cash dan dalam bentuk simpanan. hal ini merupakan suatu bentuk kemajuan hukum waris diera modern seperti sekarang.

\section{KESIMPULAN}

Melalui penjelasan di atas dapat dipahami bahwa sebelum terbentuk menjadi Republik pada tahun 1923, Turki sebelumnya menganut sistem pemerintahan kerajaan di bawah kekuasaan dinasti Utsmaniah. Mayoritas penduduk Turki adalah pengikut madzhab Hanafi. Turki adalah Negara muslim pertama yang melakukan kodifikasi undangundang keluarga di masa modern yaitu dengan lahirnya The Ottoman Law of Family Rights tahun 1917.

Undang-undang ini pernah dibekukan beberapa lama, dengan harapan akan dapat diganti dengan undang-undang yang lebih lengkap, yakni atas usulan Mustafa Kemal Pasha. Bahkan undang-undang ini diberlakukan hanya dalam dua tahun, setelah dibekukan tahun 1919. Pada tahun 1923, pemerintah membentuk panitia untuk membuat draf undang-undang baru. Akan tetapi, para ahli hukum yang diserahi tugas memperbaharui undang-undang tersebut selama lima tahun tidak berhasil membuat undang-undang dimaksud. Akhirnya Turki mengadopsi The Swiss Civil Code tahun 1912, yang dijadikan undangundang Sipil Turki (The Turkish Civil Code) tahun 1926, dengan sedikit

${ }^{51} 689$ The Turkish Civil Code 
perubahan sesuai dengan tuntutan kondisi Turki. Materi pembaharuan dalam undang-undang ini adalah seputar Hukum Perkawinan (pertunangan, umur pernikahan, mahrom, poligami, resepsi pernikahan, pembatalan pernikahan), Perceraian dan Pemisahan, Kompensasi, dan Hukum Waris

Dengan menggunakan extra doctrinal reform, Turki melakukan perubahan-perubahan terhadap pembaharuan hukum keluarga. Sehingga tercipta Undang-Undang The Turkish Civil Code. Yang berisi Hukum Perkawinan (pertunangan, umur pernikahan, mahrom, poligami, resepsi pernikahan, pembatalan pernikahan), Perceraian dan Pemisahan, Kompensasi, dan Hukum Waris.

Berdasarkan The Turkish Civil Code, Turki telah melakukan berbagai pembaharuan dalam hukum keluarga, khususnya hukum kewarisan. Wujud pembaharuan hukum kewarisan tersebut adalah Pertama, dalam hal ahli waris, yang menjadi ahli waris adalah keluarga inti, yaitu suami atau istri yang ditinggalkan dan anak (nuclear family) sedangkan kerabat di luar keluarga inti dapat menjadi ahli waris apabila berjasa ikut memelihara ahli waris atau harta warisan. Kedua, mengenai status laki-laki dan perempuan, masih ditetapkan bahwa status lakilaki dan perempuan dalam keluarga sama, sehingga tidak membedakan mereka dalam perolehan harta peninggalan. Ketiga, Undang-undang di atas sudah membuat ketentuan tentang harta warisan cash dan dalam bentuk simpanan. hal ini merupakan suatu bentuk kemajuan hukum waris diera modern seperti sekarang. 


\section{DAFTAR PUSTAKA}

The Ottoman Law of Family Rights, 1917

The Turkish Civil Code, 1926

The Turkish Family (Marriage and Divorce) Law, 1951

Hâkim, Abdul Hamid, Mabâdiu Awwaliyyah, Jakarta: Sa'adiyah Putera, tt.

Jazîrî al-, Abd al-Rahmân, al-Fiqh 'alâ Madzâhib al-Arba'ah, Beirut: Dâr al-Fikr, 1989.

Ridhâ, Muhammad Rasyid, Tafsîr al-Manâr, Mesir: al-Manâr, 1325 H, Vol. IV.

Shahîr al-, Muhammad Amin, Hâsyiyah Radd al-Mukhtâr, vol. II, Beirut: Dâr al-Fikr, tt.

Shahrur, Muhammad, Nahwa Ushûl al-Jadîdah li al-Fiqh al-Islamî; Fiqh al-Mar'ah, Damaskus: Ahâli, 2000.

Syafi'i al-, Muhammad Qasim al-Ghazi, Fath al-Qârib, Surabaya: Maktabah Muhammad bin Ahmad bin Nabhan wa Auladuhu, tt.

Zuhailî az-, Wahbah, al-Fiqh al-Islâmî wa adillatuh, cet. Ke-3, Beirut: Dâr al-Fikr,1989, Vol. VII.

Ahmed, Akbar S., Discovering Islam, Making Sense of Muslim History and Society, London\&New York: Routledge\&Kegan Paul, 1988.

........, Living Islam: from Samarkand to Stornoway, New York: Facts on File, 1994.

Anderson, J.N.D., Islamic Law in the Modern World, New York: New York University, 1959.

.........., Law Reform in the Muslim World, London: The Athlone Press, 1976.

Pearl, David and Werner Menski, Muslim Family Law, third edition, London: Sweet and Maxwell, 1998.

Jackson, Sherman A., Islamic Law and The State: The Continental Jurisprudence of Shihâb al-Dîn al-Qarâfî, Netherland: E.J. Brill, 1996. 
Lewis, Bernad, The Middle East: A Brief History of The Last 2000 Years, New York: Scribner, 1996.

Mahmood, Tahir, Family Law Reform in The Muslim World, New Delhi: N.M. TRIPATHI PVT. LTD., 1972.

........... Personal Law in Islamic Countries; History, Text, Comparative Analysis, New Delhi: Academy of Law and Religion, 1987.

Minhaji, Akh., Islamic Law and Local Tradition: A Socio-Historical Approach, Yogyakarta: Kurnia Kalam Semesta, 2008.

Sigelman, Carol K. dan David R. Shaffer, Life Span Human Development, California: Brooks/Cole Publishing Company, 1995.

Abyan, H. Amir, dkk., Fiqh Untuk Madrasah Tsanawiyah III, Semarang: Thoha Putera, 1996.

Ahmed, Akbar S., Citra Muslim: Tinjauan sejarah dan Sosiologi, alih bahasa Nunding Ram dan H. Ramli Yakub, Jakarta: Erlangga, 1992.

Amir, Dja'far, Ilmu Fiqih, Solo: Ramadhani, 1986.

Anderson, J.N.D., Hukum Islam di Dunia Modern, alih bahasa Machnun Husein, Surabaya: Amarpress, 1990.

Ayyub, Syaikh Hasan, Fikih Keluarga, Jakarta: Pustaka Al-Kautsâr, 2006.

Darajat, Zakiah, Ilmu Fiqh II, Jakarta: Dana Bhakti Wakaf, 1995.

Desmita, Psikologi Perkembangan, Bandung: PT. Remaja Rosdakarya, 2005.

Habsyi al-, Muhammad Bagir, Fiqih Praktis Menurut al-Qur'an, al-Sunnah dan Pendapat Para Ulama', Bandung: Mizan, 2002.

Hutabarat, Herbert, dkk., Naskah Lengkap Kongres Obstetri dan Genekologi Indonesia Ketiga, Medan: KOGI, 1976.

Idris, Abdul Fatah dan Abu Ahmadi, Fiqih Islam Lengkap, Jakarta: Rineka Cipta, 1994.

Lapidus, Ira M., Sejarah Sosial Ummat Islam; Bagian Ketiga, alih bahasa Ghufron A. Mas'adi, Jakarta: PT. Raja Grafindo Persada, 1999.

Maghlûts al-, Sami bin Abdullah, Atlas Perang Salib: Mengungkap Peristiwa Berdarah Abad Pertengahan, alih bahasa Fuad Syaifuddin Nur 


\section{(Jakarta Timur: Almahira, 2009}

Mubarok, Ahmad Zaki, Pendekatan Strukturalisme Linguistik dalam Tafsir al-Qur'an Kontemporer "ala" M. Syahrur, Yogyakarta: elSAQ Press, 2007.

Mughniyah, Muhammad Jawad, Fiqih Lima Madzhab: Ja'farî, Hanafî, Malikî, Syafi'̂, Hanbalî, alih bahasa Masykur A. B. dkk., cet. Ke-10, Jakarta: PT. Lentera Basritama, 2003.

Mustaqim, Abdul dan Sahiron Syamsuddin (ed.), Studi al-Qur'an Kontemporer; Wacana Baru Berbagai Metodologi Tafsir, Yogyakarta: PT. Tiara Wacana Yogya, 2002.

Muzdhar, H. M. Atho' dan Khoiruddin Nasution (ed.), Hukum Keluarga di Dunia Islam Modern, Jakarta: Ciputat Press, 2003.

Nasution, Khoiruddin, Status Wanita di Asia Tenggara: Studi Terhadap Perundang-Undangan Perkawinan Muslim Kontemporer di Indonesia dan Malaysia, Jakarta: INIS, 2002.

Rahman, Fazlur, Islam, alih bahasa Ahsin Mohammad, cet. Ke-IV, Bandung: Pustaka, 2000.

Rofiq, Ahmad, Hukum Islam di Indonesia,cet. Ke-2, Jakarta: PT. Raja Grafindo Persada, 1997.

Sabiq, Sayyid, Fiqh Sunnah, alih bahasa Nor Hasanuddin, Jakarta: Pena Pundi Aksara, 2007, I-IV.

Shahrur, Muhammad, Metodologi Fiqih Islam Kontemporer, alih bahasa Sahiron Syamsuddin dan Burhanuddin, Yogyakarta: elSAQ, 2004.

.......... Prinsip dan Dasar Hermeneutika al-Qur'an Kontemporer, alih bahasa Sahiron Syamsudin dan Burhanudin Dzikri, Yogyakarta: eLSAQ, 2004.

........, Prinsip dan Dasar Hermeneutika Hukum Islam Kontemporer, alih bahasa Sahiron Syamsudin dan Burhanuddin Dzikri (Yogyakarta: elSAQ Press, 2007

Tim Proyek Pembinaan Prasarana dan Sarana Perguruan Tinggi Agama/ IAIN di Jakarta, Ilmu Figh II, Jakarta: DEPAG, 1985.

Zulkifli L., Psikologi Perkembangan, Bandung: PT. Remaja Rosdakarya, 2006. 
Dictionary of Sociology, Henry Pratt Fairchild, Totowa: Adams Littlefield, 1977.

Kamus Ilmiah Populer, Pius A. Partanto dan M. Dahlan Al-Barry, Surabaya: Arkola, 1994.

The world book of Encyclopedia, Turki, Vol. 19, USA: World book Inc., 1997.

Gupta, Kiran, "Polygamy Law Reform in Modern Muslim States: A Study in Comparative Law," dalam Islamic and Comparative Law Review, vol. xii, no.2, ttp.: Summer, 1992, hlm. 114-154.

Isroqunnajah, "Hukum Keluarga Islam di Republik Turki," dalam M. Atho' Muzdhar dan Khoiruddin Nasution (ed.), Hukum Keluarga di Dunia Islam Modern, Jakarta: Ciputat Press, 2003, hlm. 36-52.

Muslehuddin, Muhammad, "Islamic Social System," dalam Studies in Islamic Law, Religion and Sosiety, New Delhi: H.S. Bathia, 1989, hlm. 334-347.

Nasr, Seyyed Hossein, "Islam," dalam Arvind Sharma (ed.), Our Religious, New York: Harper Collins, 1993.

Tholib, Udjang, "The Relation Between the Kanûn and the Sharîa in the Ottoman Empire (15 th $-17^{\text {th }}$ Centuries)," dalam Islam $\mathbb{E}$ Development: A Politico Religious Response, Jakarta: Titian Ilahi Press, 1997. 